\title{
First- and Second-Trimester Reference Intervals for Thyroid Hormones during Pregnancy in "Rhea" Mother-Child Cohort, Crete, Greece
}

\author{
Polyxeni Karakosta, ${ }^{1,2}$ Leda Chatzi, ${ }^{1}$ Emmanouil Bagkeris, ${ }^{1}$ Vasiliki Daraki, ${ }^{3}$ \\ Dimitris Alegakis, ${ }^{1}$ Elias Castanas, ${ }^{2}$ Manolis Kogevinas, ${ }^{4,5}$ and Marilena Kampa ${ }^{2}$ \\ ${ }^{1}$ Department of Social Medicine, Faculty of Medicine, University of Crete, P.O. Box 2208, 71003 Heraklion, Greece \\ ${ }^{2}$ Department of Experimental Endocrinology, Faculty of Medicine, University of Crete, P.O. Box 2208, 71003 Heraklion, Greece \\ ${ }^{3}$ Department of Endocrinology, Faculty of Medicine, University of Crete, 71003 Heraklion, Greece \\ ${ }^{4}$ Centre for Research in Environmental Epidemiology (CREAL), Doctor Aiguader, 88, 08003 Barcelona, Spain \\ ${ }^{5}$ National School of Public Health, Alexandras Avenue 196, 11521 Athens, Greece
}

Correspondence should be addressed to Polyxeni Karakosta, p_karakosta@hotmail.com

Received 4 May 2011; Revised 26 August 2011; Accepted 9 September 2011

Academic Editor: Duncan Topliss

Copyright (c) 2011 Polyxeni Karakosta et al. This is an open access article distributed under the Creative Commons Attribution License, which permits unrestricted use, distribution, and reproduction in any medium, provided the original work is properly cited.

\begin{abstract}
Estimation and interpretation of thyroid function tests in pregnant women is of utmost importance for maternal, fetal and neonatal health. Our objective was to calculate laboratory- and geography-specific reference intervals for thyroid hormones during pregnancy in an iodine-sufficient area of the Mediterranean, Crete, Greece. This project was performed in the context of "Rhea" mother-child cohort. Fulfillment of extensive questionnaires and estimation of free triiodothyronine (fT3), free thyroxine (fT4), thyroid-stimulating hormone (TSH), and antithyroid antibodies were performed. The reference population was defined using inclusion criteria regarding thyroidal, obstetric, and general medical status of women. Reference interval for TSH was $0.05-$ $2.53 \mu \mathrm{IU} / \mathrm{mL}$ for the first and $0.18-2.73 \mu \mathrm{IU} / \mathrm{mL}$ for the second trimester. $6,8 \%$ and $5,9 \%$ of women in the first and second trimester, respectively, had TSH higher than the upper reference limit. These trimester-specific population-based reference ranges are essential in everyday clinical practice for the correct interpretation of thyroid hormone values and accurate classification of thyroid disorders.
\end{abstract}

\section{Introduction}

Pregnancy is a period of significant hormonal changes and metabolic demands which result in complex effects on thyroid function [1-3]. More specifically, alterations in iodine metabolism [1], production of $\beta$-chorionic gonadotropin $(\beta$-hCG $)$, and increases in both thyroid hormone-binding proteins and thyroid hormones per se $[4,5]$ are some of the physiologic changes that occur during normal pregnancy. At the same time, thyroid hormones play a critical role in neonatal and child neurodevelopment [6], and maternal thyroid disorders can lead to obstetric complications and irreversible effects on the fetus [7]. These findings point out the need for all pregnant women to be screened for thyroid disorders with a valid biomarker with distinct reference ranges.

In the past years, a number of studies from different regions have developed reference ranges for thyroid hormones during pregnancy women [8-31]; however these results should not be extrapolated due to differences in ethnicity, iodine intake, and immunometric assay applied in each study. Moreover, the methodology used for the determination of the reference population (choice of reference population, sample size, assessment of outliers) differs across studies resulting in a variation of absolute reference limits.

The aim of this study was to develop laboratory- and geography-specific reference intervals for thyroid hormones 
(thyroid-stimulating hormone (TSH), and free triiodothyronine (free T3), free thyroxine (free T4)) during pregnancy in an iodine-sufficient area of the Mediterranean, Crete, Greece.

\section{Materials and Methods}

2.1. Study Population. This project utilized data from the Rhea mother-child cohort, in the island of Crete, Greece. The mother-child "Rhea" study is a prospective cohort study examining a population sample of pregnant women and their children in a prefecture of southern Greece. Pregnant women, who became pregnant within one year, starting February 2007, participated in the study. The first contact was done at the time of the first major ultrasound, and women were divided in trimesters of pregnancy, according to gestational age which was defined by last menstrual period and ultrasound (first: <13 weeks, second: 13-27 weeks, and third trimester: $>28$ weeks). Participants were interviewed, and blood samples were collected and stored in $-80^{\circ} \mathrm{C}$. Extensive questionnaires were completed, and standardized information from ultrasounds was collected together with data from clinical records during pregnancy and birth. The study was approved by the corresponding ethical committees, and all participants provided written informed consent.

From the entire population of the Rhea cohort $(n=$ $1610)$, all available serum samples were analyzed for thyroid hormone measurements $(n=1300)$. According to the recommendations of the National Academy of Clinical Biochemistry (NACB) [32], we subsequently excluded women with a self-reported thyroidal dysfunction (goiter, cancer, hyper-, and hypo-thyroidism), a laboratory diagnosis of overt hypo- or hyperthyroidism (i.e., abnormal values of TSH and FT4 using the reference ranges of the assay used), evidence for autoimmune thyroid disease (elevated antiTPO and anti-Tg), past or present use of thyroid medications, parental history of any thyroid illness, and women with incomplete information regarding thyroid function. In addition, women with multiple or complicated pregnancies (hyperemesis, gestational diabetes or hypertension, perinatal infections, and stillbirths), clinical diagnosis of a chronic or autoimmune disease (diabetes, hypertension, asthma, inflammatory bowel disease, tumors, and others), and a past history of spontaneous abortions were also removed from the reference population (Figure 1).

2.2. Laboratory Analysis. For each sample, TSH, free thyroxine (free T4), free triiodothyronine (free T3), and antithyroid antibodies (antithyroperoxidase [anti-TPO] and antithyroglobulin [anti-Tg]) were measured by IMMULITE 2000 immunoassay system (Siemens Healthcare Diagnostics, ILL 60015-0778, USA). For TSH, inter- and intra-assay variability were $<5.3 \%$ and $<6.4 \%$, respectively, for levels of $0.32-39 \mathrm{mIU} / \mathrm{mL}$. Accordingly, for free T4 these values were $<7.8 \%$ and $<7.1 \%$ for the level of $0.51-4.82 \mathrm{ng} / \mathrm{dL}(6.56-$ $62.03 \mathrm{pmol} / \mathrm{L})$, for free T3 $<9.1 \% \&<10 \%$ for the level of $2.5-13 \mathrm{pg} / \mathrm{mL}(3.84-19.96 \mathrm{pmol} / \mathrm{L})$, for anti-Tg $<4.9 \%$ and $<5.8 \%$, and for anti-TPO $<7.4 \%$ and $7.2 \%$. The proposed reference limits of the manufacturer for normal euthyroid adults were: free T3: $1.8-4.2 \mathrm{pg} / \mathrm{mL} \quad(2.76-6.45 \mathrm{pmol} / \mathrm{L})$, free T4: $0.89-1.76 \mathrm{ng} / \mathrm{dL}$ (11.5-22.7 pmol/L), and TSH: $0.4-$ $4 \mu \mathrm{IU} / \mathrm{mL}$. Anti-TPO and anti-Tg were considered elevated if levels were $\geq 35 \mathrm{IU} / \mathrm{mL}$ and $>40 \mathrm{IU} / \mathrm{mL}$, respectively.

2.3. Statistical Analysis. All data were analyzed by SPSS 17 for windows. The nature of the underlying distribution of free T3, free T4, and TSH for the reference population was examined by inspecting normality tests, histograms and Pplots. In case of a significant variation from normal distribution, a logarithm transformation ( $\log$ and $\ln$ ) was applied to achieve normality. Outliers were identified using box plots. For the identified outliers Dixon's $Q$ test was applied to the least extreme; if the test rejects the least extreme outlier, then the more extreme outliers are also rejected. Continuously, when the data followed a Gaussian distribution or were transformed to a normal distribution, reference intervals were computed as follows: mean $\pm 1.96 \times$ standard deviation. If normality was not achieved, even after transformation or after the outlier deletion, a nonparametric method was applied to estimate the reference intervals, by computing the rank numbers of 2.5th and the 97.5th percentiles to estimate the lower and the higher limits of the reference interval, respectively.

Thyroid hormones were expressed as mean, median, standard deviation, 2.5th and 97.5th percentile for the 1st and 2 nd trimester. The Mann-Whitney $U$ test was used to compare differences for the 2 trimesters for a level of significance of $P<0.05$.

\section{Results}

3.1. Total Study Population. Starting from a total cohort population of 1610 pregnant women, 1300 samples were available for thyroid function and antibody analyses. Of them, $35.2 \%$ were in the first ( $<13$ weeks), $61 \%$ in the second (13-27 weeks), and 3.7\% in the third trimester ( $>28$ weeks) of pregnancy (Table 1 ). The age of the mothers varied from 15 to 45 years, and the majority of mothers were of Greek origin $(85.3 \%)$. History of spontaneous miscarriages was present in 223 women $(17.2 \%)$. Considering thyroid function, $389(29.9 \%)$ of mothers had a positive family history of thyroidal disease, while 165 (12.7\%) and 87 $(6.7 \%)$ women had elevated levels of anti-TPO and anti-TG antibodies, respectively.

3.2. Reference Population. After implementation of the aforementioned exclusion criteria, a total of 875 women were excluded from the study (Figure 1, Table 1), resulting to a final population of 425 women (1st trimester: 143, 2nd trimester: 260, 3rd trimester: 22). Women in the third trimester $(n=22)$ were excluded from the analysis, since the sample size was not adequate for the estimation of reference intervals to a reasonable degree of precision. The final population (403 women) was used to determine the reference limits and the $95 \%$ confidence intervals for TSH, free T4, and free T3 for the first and second trimester of pregnancy. 


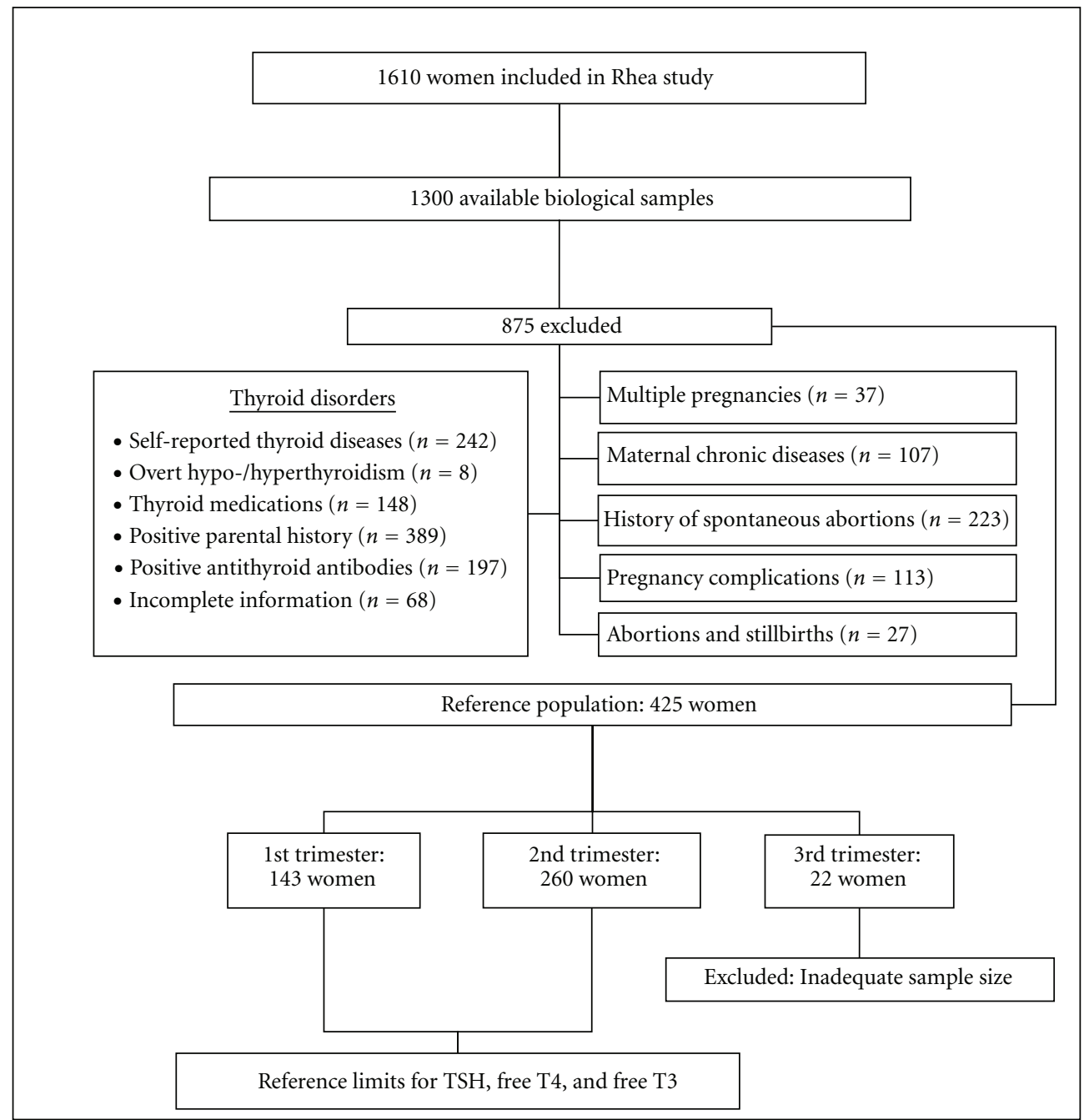

Figure 1: Flow diagram of the study process for the determination of the reference population.

TABLE 1: Demographic data for pregnant women in total and reference study population.

\begin{tabular}{|c|c|c|c|c|c|}
\hline & \multicolumn{3}{|c|}{ Total study population ${ }^{\mathrm{a}}$} & \multicolumn{2}{|c|}{ Reference population } \\
\hline & 1st trimester & 2nd trimester & 3rd trimester & 1st trimester & 2nd trimester \\
\hline Sample size $(n)$ & 458 & 794 & 48 & 143 & 260 \\
\hline Age $(\text { years })^{\mathrm{b}}$ & $29.16(5.12)$ & $28.98(5.19)$ & $28.37(4.61)$ & $28.50(5.09)$ & $27.79(4.95)$ \\
\hline Greek origin $n(\%)$ & $369(80.6)$ & $698(87.9)$ & $42(87.5)$ & $114(79.7)$ & $221(85)$ \\
\hline
\end{tabular}

${ }^{\mathrm{a}}$ Women with available biological samples.

${ }^{\mathrm{b}}$ Values are expressed as mean (SD).

3.3. Reference Values for Thyroid Hormones. Figure 2 shows the box plots for TSH, free T3, and free T4 for first and second trimester after the outlier assessment. Additionally, mean values, standard deviations, medians, and the 2.5th and 97.5th percentiles for all thyroid hormones according to trimester are shown in Table 2.

According to our results (Tables 2 and 3), the reference intervals of serum TSH levels for the first trimester were $0.05-2.53 \mu \mathrm{IU} / \mathrm{mL}$, of free T3 $1.54-5.22 \mathrm{pg} / \mathrm{mL}$ (2.37$8.02 \mathrm{pmol} / \mathrm{L})$, and of free T4 $0.95-1.53 \mathrm{ng} / \mathrm{dL}$ (12.23$19.69 \mathrm{pmol} / \mathrm{L})$. For the second trimester, respective reference intervals were: $0.18-2.73 \mu \mathrm{IU} / \mathrm{mL}$ for TSH, $1.78-5.29 \mathrm{pg} / \mathrm{mL}$ (2.73-8.13 pmol/L) for free T3, and 0.87-1.45 ng/dL (11.20$18.66 \mathrm{pmol} / \mathrm{L}$ ) for free T4. Median TSH and free T3 values showed a slight increase in 2nd trimester, while median free T4 values fell as gestational age advanced.

Mann Whitney $U$ test revealed significant differences between trimesters for free T4 $(P$ value $<0.001)$, while respective $P$ values for TSH and free T3 were 0.058 and 0.054 . These findings justify the separation of groups into different trimesters (Table 2, Figure 2). 


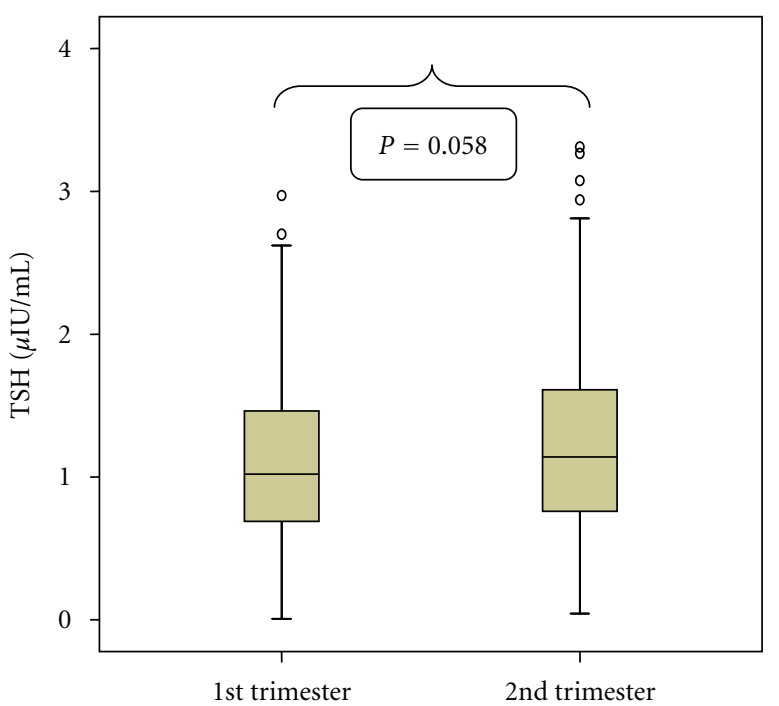

(a)

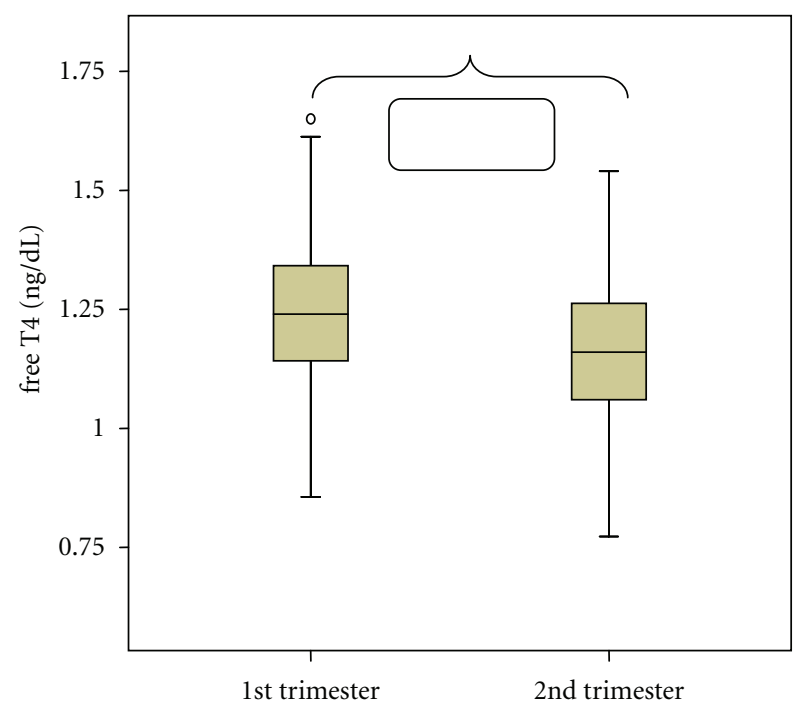

(b)

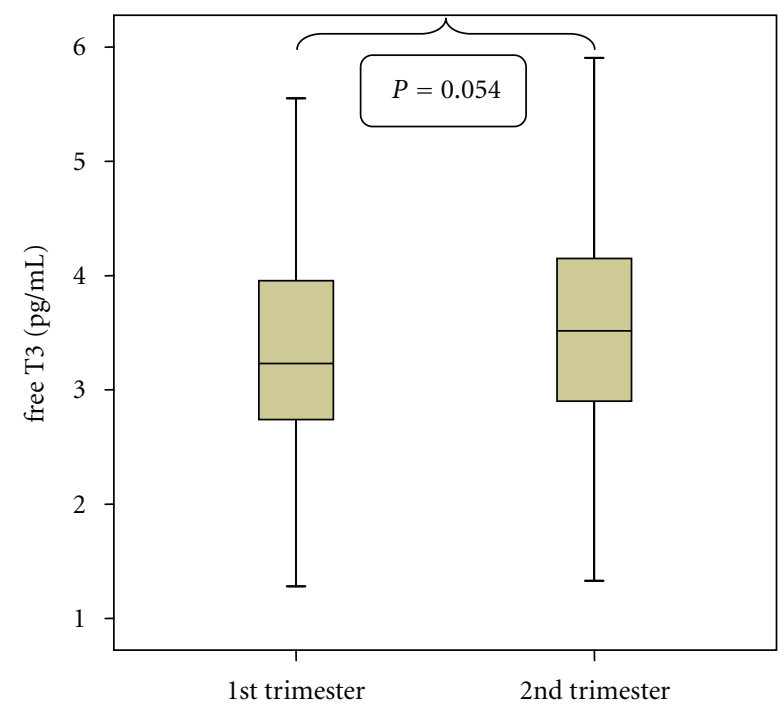

(c)

Figure 2: Box plot of TSH, free T3, and free T4 concentrations in the reference population during the 1st and 2nd trimester of gestation. TSH: thyroid-stimulating hormone; Free T3: free triiodothyronine; free T4: free thyroxine Differences between first and second trimester are shown with $P$ values $(P=0.058$ for TSH, $P=0.054$ for free T3, $P<0.001$ for free T4).

As shown in Table 4, if the reference limits of the manufacturer were applied to our entire cohort, misclassification of maternal thyroid clinical entities would occur. More specifically, 47 and 43 women with TSH concentrations that are normal for the first and second trimester, respectively would have been misclassified as having subclinical hyperthyroidism. Conversely, 25 and 29 women with a TSH above the first and second trimester-specific upper reference limit would not have been identified as subclinical hypothyroidism.

\section{Discussion}

During pregnancy several hormonal changes and metabolic demands occur, resulting in complex effects on thyroid function [3]. Alterations in the pituitary-thyroid axis include an increase in thyroid hormone-binding globulin along with increases in total T4, T3 as well as serum thyroglobulin (TG). Additionally, iodine clearance by the kidneys is enhanced during gestation, while the mild thyrotropic effects of rising $\beta$-hCG may exert negative feedback on TSH secretion [33] wrongly suggesting hyperthyroidism in normal pregnant women of the 1st trimester [1].

The incidence of overt and subclinical hypothyroidism in pregnant women has been estimated to be around 0.30.5 and $2-3 \%$, respectively [34]. Recent studies have shown that untreated hypothyroidism during pregnancy increases the incidence of maternal anemia, preeclampsia, postpartum hemorrhage, placental abruption, and spontaneous abortion and may cause low birth weight, prematurity, congenital malformations, and impaired fetal brain development with 
TABLE 2: Thyroid hormones according to gestational age, Rhea mother-child cohort, Crete, Greece.

\begin{tabular}{|c|c|c|c|c|c|c|c|c|}
\hline & $N$ & Distribution & 2.5th percentiles & 97.5th percentile & Median & Mean & $\mathrm{SD}$ & Reference range \\
\hline \multicolumn{9}{|l|}{ 1st trimester } \\
\hline $\mathrm{TSH}^{\mathrm{a}} \mu \mathrm{IU} / \mathrm{mL}$ & 141 & Not normal & 0.05 & 2.53 & 1.02 & 1.08 & 0.61 & $0.05-2.53$ \\
\hline free $\mathrm{T}^{\mathrm{b}} \mathrm{pg} / \mathrm{mL}(\mathrm{pmol} / \mathrm{L})$ & 141 & Normal $^{\mathrm{d}}$ & $1.84(2.83)$ & $5.39(8.28)$ & $3.21(4.93)$ & $3.38(5.19)$ & $0.94(1.44)$ & $\begin{array}{c}1.54-5.22 \\
(2.37-8.02)\end{array}$ \\
\hline free $\mathrm{T} 4^{\mathrm{c}} \mathrm{ng} / \mathrm{dL}(\mathrm{pmol} / \mathrm{L})$ & 139 & Normal $^{\mathrm{e}}$ & $0.96(12.36)$ & $1.60(20.59)$ & $1.24(15.96)$ & $1.24(15.96)$ & $0.15(1.93)$ & $\begin{array}{c}0.95-1.53 \\
(12.23-19.69) \\
\end{array}$ \\
\hline \multicolumn{9}{|l|}{ 2nd trimester } \\
\hline $\mathrm{TSH}^{\mathrm{a}} \mu \mathrm{IU} / \mathrm{mL}$ & 257 & Not normal & 0.18 & 2.73 & 1.14 & 1.23 & 0.65 & $0.18-2.73$ \\
\hline free $\mathrm{T} 3^{\mathrm{b}} \mathrm{pg} / \mathrm{mL}(\mathrm{pmol} / \mathrm{L})$ & 256 & Normal & $1.99(3.06)$ & $5.30(8.14)$ & $3.52(5.41)$ & $3.55(5.45)$ & $0.87(1.34)$ & $\begin{array}{c}1.78-5.29 \\
(2.73-8.13)\end{array}$ \\
\hline free $\mathrm{T} 4^{\mathrm{c}} \mathrm{ng} / \mathrm{dL}(\mathrm{pmol} / \mathrm{L})$ & 258 & Normal & $0.84(10.81)$ & $1.44(18.53)$ & $1.16(14.93)$ & $1.16(14.93)$ & $0.15(1.93)$ & $\begin{array}{c}0.87-1.45 \\
(11.20-18.66)\end{array}$ \\
\hline
\end{tabular}

TSH: thyroid-stimulating hormone; free T3: free triiodothyronine; free T4: free thyroxine.

${ }^{a}$ Difference between first and second trimester: $P=0.058$.

${ }^{\mathrm{b}}$ Difference between first and second trimester: $P=0.054$.

${ }^{c}$ Difference between first and second trimester: $P<0.001$.

${ }^{\mathrm{d}}$ After outlier deletion and $\log$ transformation.

eAfter outlier deletion.

TABLE 3: Comparison between reference ranges for thyroid hormones as calculated by our analysis and those proposed by the manufacturer.

\begin{tabular}{lcccccc}
\hline \multirow{2}{*}{ Reference ranges } & \multicolumn{2}{c}{$\mathrm{TSH}(\mu \mathrm{IU} / \mathrm{mL})$} & \multicolumn{2}{c}{ free $\mathrm{T} 4(\mathrm{ng} / \mathrm{dL})$} & \multicolumn{2}{c}{ free T3 $(\mathrm{pg} / \mathrm{mL})$} \\
& 1st trimester & 2nd trimester & 1st trimester & 2nd trimester & 1st trimester & 2nd trimester \\
\hline $\begin{array}{l}\text { Rhea cohort } \\
\text { Manufacturer }\end{array}$ & $0.05-2.53$ & $0.18-2.73$ & $0.95-1.53$ & $0.87-1.45$ & $1.54-5.22$ & $1.78-5.29$ \\
\hline
\end{tabular}

TSH: thyroid-stimulating hormone; free T3: free triiodothyronine; free T4: free thyroxine.

TABLE 4: Thyroid clinical entities in the general population of Rhea mother-child cohort based on: (i) the manufacturer's and (ii) the derived reference limits.

\begin{tabular}{|c|c|c|c|c|c|c|}
\hline Trimester & $\begin{array}{l}\text { Reference } \\
\text { limits }\end{array}$ & $\begin{array}{l}\text { Normal thyroid } \\
\text { function } n(\%)^{\mathrm{a}}\end{array}$ & $\begin{array}{c}\text { Subclinical } \\
\text { hypothyroidism } \\
n(\%)^{\mathrm{b}}\end{array}$ & $\begin{array}{c}\text { Clinical } \\
\text { hypothyroidism } \\
n(\%)^{\mathrm{c}}\end{array}$ & $\begin{array}{c}\text { Subclinical } \\
\text { hyperthyroidism } \\
n(\%)^{\mathrm{d}}\end{array}$ & $\begin{array}{c}\text { Clinical hyper- } \\
\text { thyroidism } n \\
(\%)^{\mathrm{e}}\end{array}$ \\
\hline \multirow{2}{*}{1 st } & Manufacturer & $386(84.3)$ & $6(1.3)$ & $0(0)$ & $48(10.5)$ & $7(1.5)$ \\
\hline & Rhea cohort & $371(81.0)$ & $31(6.8)$ & $0(0)$ & $1(0.2)$ & $10(2.2)$ \\
\hline \multirow{2}{*}{2 nd } & Manufacturer & $680(86.6)$ & $18(2.3)$ & $1(0.1)$ & $61(7.7)$ & $1(0.1)$ \\
\hline & Rhea Cohort & $653(82.2)$ & $47(5.9)$ & $0(0)$ & $18(2.3)$ & $9(1,1)$ \\
\hline
\end{tabular}

${ }^{a}$ TSH between reference limits and free T4 between reference limits.

${ }^{\mathrm{b}} \mathrm{TSH}$ over the upper limit of reference limits and free T4 between reference limits.

${ }^{\mathrm{C}} \mathrm{TSH}$ over the upper limit of reference limits and free T4 under the lower limit of reference limits.

${ }^{\mathrm{d}} \mathrm{TSH}$ under the lower limit of reference limits and free T4 between reference limits.

${ }^{\mathrm{e}} \mathrm{TSH}$ under the lower limit of reference limits and free T4 over the upper limit of reference limits.

decreased intelligence quotient (IQ) of children [35]. Conversely, hyperthyroidism has been described in about $0.2 \%$ of women during pregnancy [36] and may lead to preeclampsia, stillbirths, preterm delivery, intrauterine growth retardation, and low birth weight [7]. Withstanding the above, the serial changes in serum thyroid hormone levels imply the need to better define "pregnancy-specific" normative reference ranges for thyroid function tests for early diagnosis of hyperand hypothyroidism during pregnancy.

Our study represents the first study performed in a Mediterranean area, the island of Crete, within an iodine-suf- ficient country, Greece [37]. It provides reference ranges for thyroid hormones during the first and second trimester of pregnancy. International guidelines recommend determining serum TSH as the first-line screening variable for thyroid dysfunction before conception [38] and during pregnancy $[3,39]$. According to our results and in agreement with previous studies [40], the derived reference intervals for TSH were different (narrower and lower) from those proposed by the manufacturer. More specifically, our TSH reference intervals were $0.05-2.53$ and $0.18-2.73 \mu \mathrm{IU} / \mathrm{mL}$ for the first trimester and second trimester, respectively, compared 


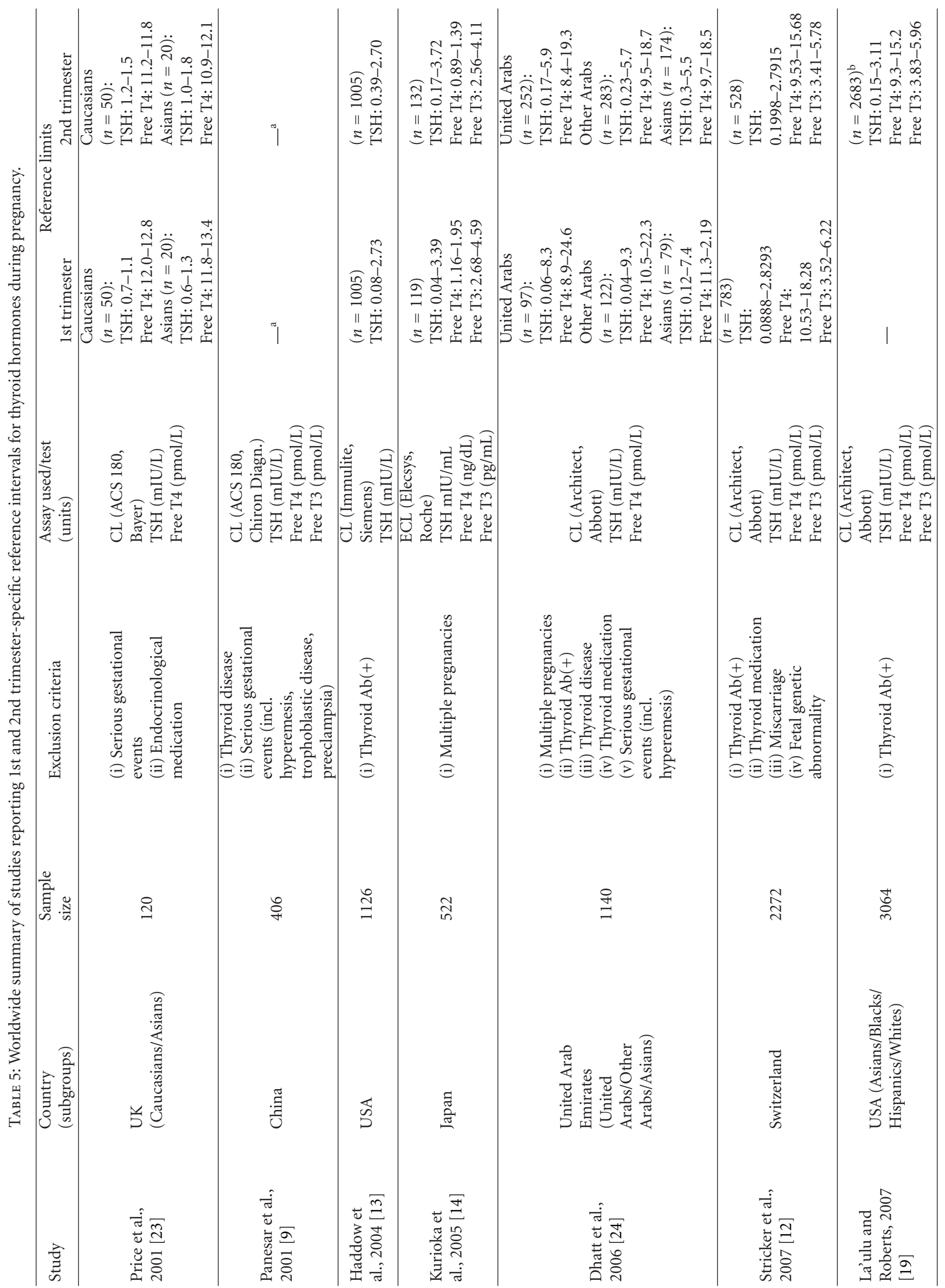




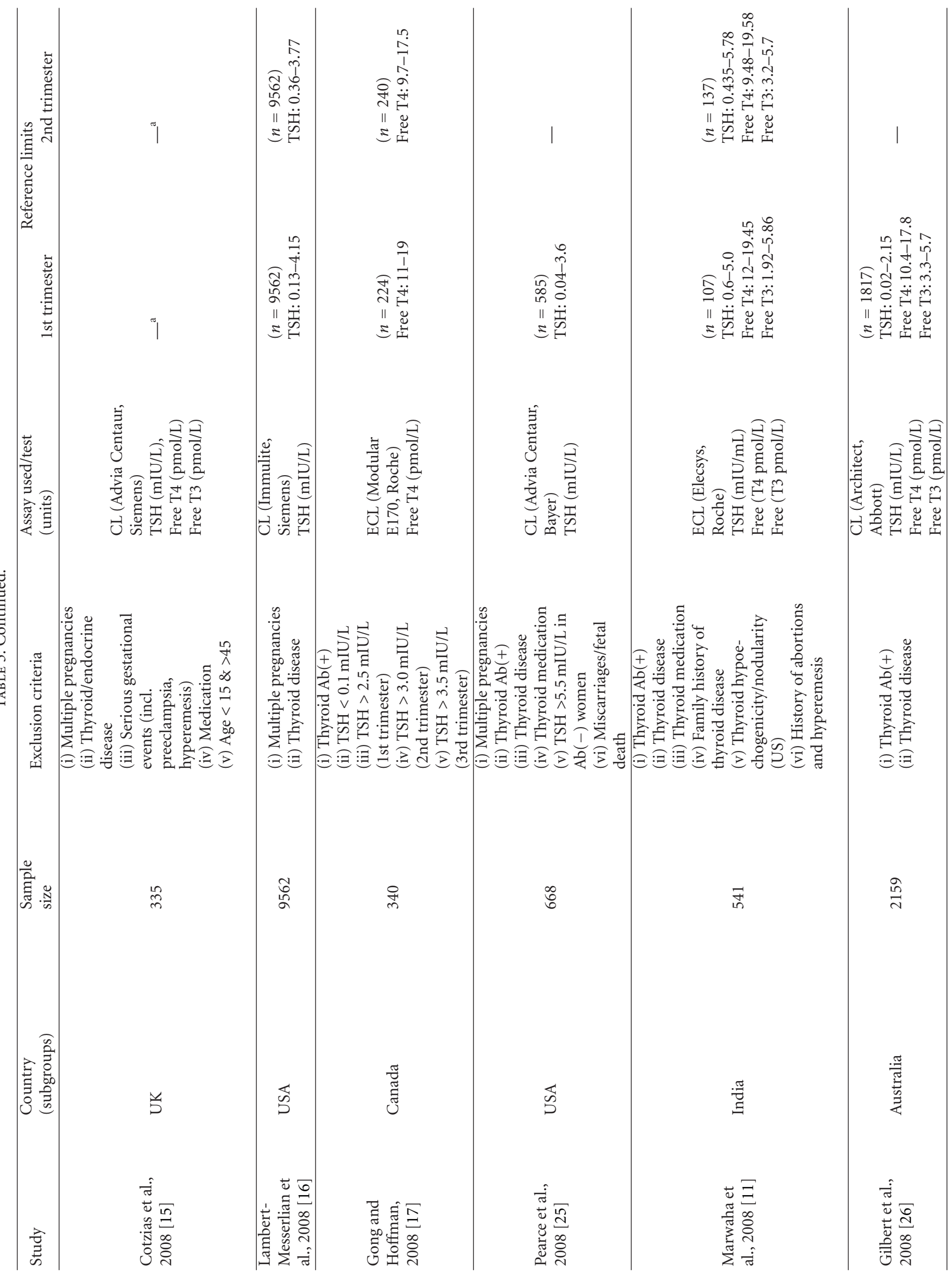




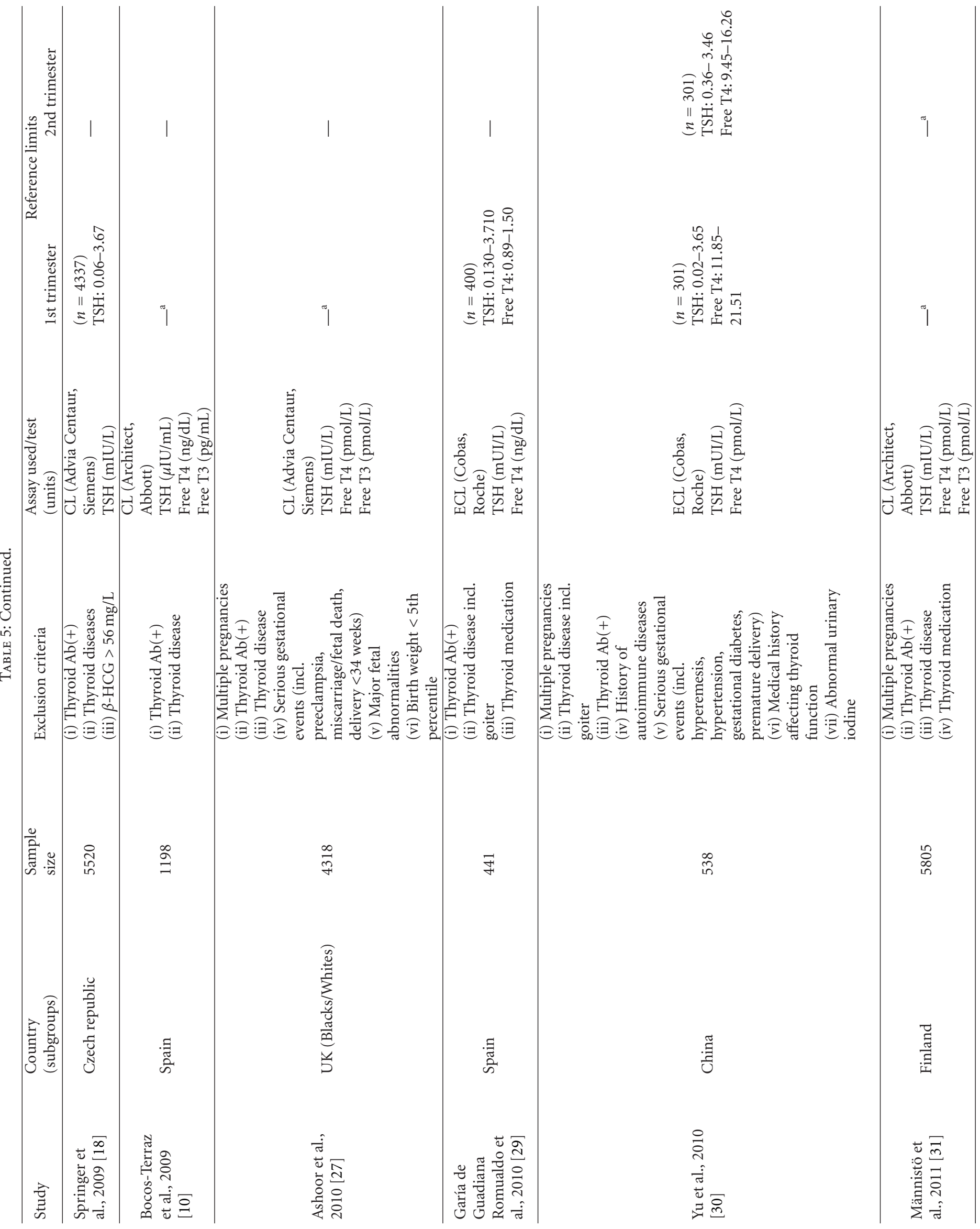




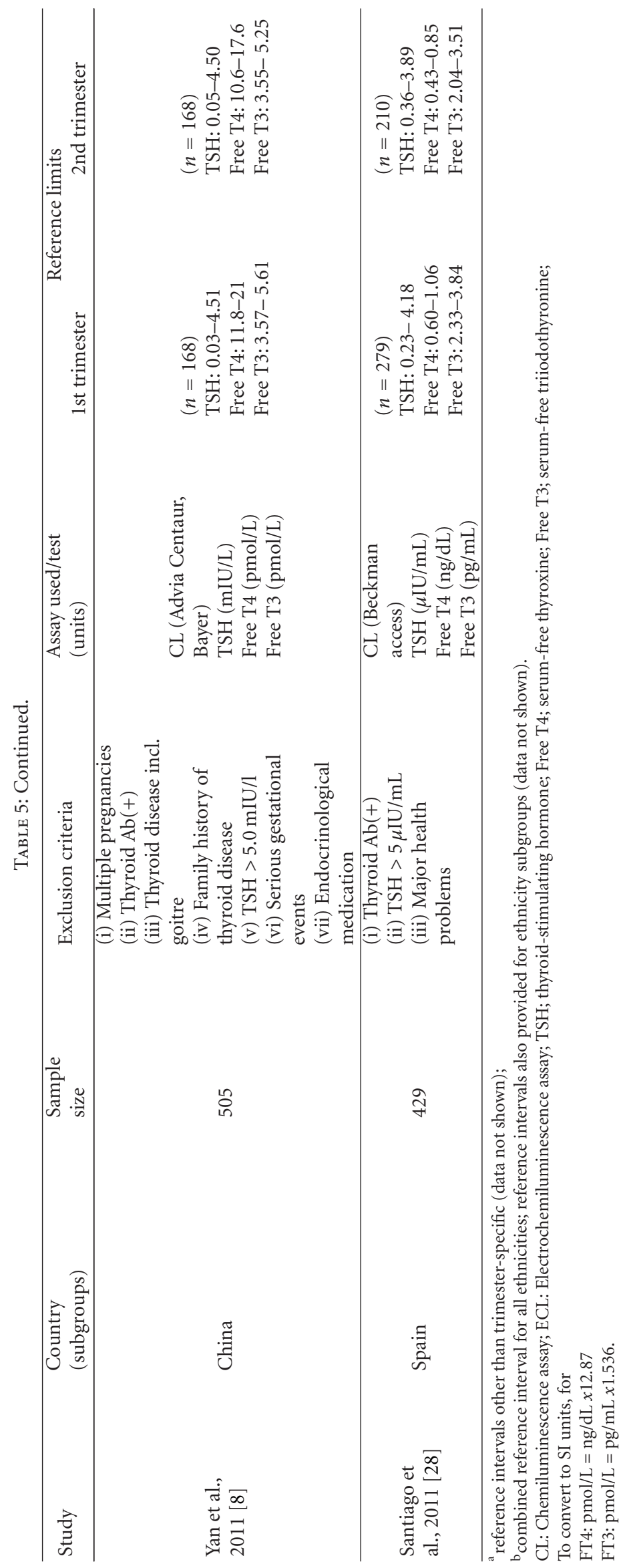


to $0.4-4 \mu \mathrm{IU} / \mathrm{mL}$. Consequently, women with subclinical hypothyroidism would not have been identified, and normal women would have been misclassified as having subclinical hyperthyroidism if the manufacturer's TSH limits were used. Regarding free T4, and free T3, our intervals were only slightly different.

Many cross-sectional studies have reported trimesterspecific reference ranges for free T3, free T4, and TSH among pregnant women [8-31]. However these reported reference ranges vary due to differences in ethnicity, iodine intake, sample size, assessment of reference population, and immunometric assay used among studies. Table 5 summarizes 1 st and 2 nd trimester-specific reference intervals for thyroid hormones from 21 studies worldwide. Ethnic disparities along with variations in iodine nutrition characteristics result in geographic variability of hormonal values. In addition, different reagents used by laboratories recognize distinct circulating TSH isoforms with resulting fluctuations even for the same sample [41]. Therefore, there is a growing need for laboratory- and geography- specific reference intervals [42]. Moreover, the methodology used by the published studies to date varies in terms of inclusion criteria for the determination of reference population, sample size, and assessment of outliers. More specifically, most studies used nonparametric methods in order to provide reference intervals without reporting the underlying distribution $[10,12$, $14,19]$, did not mention whether outliers were detected and removed [10-20], and most importantly, in some cases, have not applied strict criteria to obtain a welldefined healthy population $[13,14,16,17]$. According to the National Academy of Clinical Biochemistry (NACB) [32] and the National Health and Nutrition Examination Survey (NHANES), this well-defined healthy population should be based on specific exclusion criteria and represents the most important prerequisite for the determination of reference intervals $[43,44]$.

Based on the above, we selected our reference population from a large pool of Rhea mother-child cohort in Crete, after implementation of stringent criteria. Initially, we excluded all mothers with any kind of thyroid abnormality since women positive for thyroid autoantibodies typically have higher TSH values and therefore affect and skew the upper reference limit $[45,46]$. In addition, women with twin pregnancies or with hyperemesis gravidum were also removed from the reference population due to their potential for low TSH values (higher serum hCG) and interference with the lower limit of TSH reference range $[22,47,48]$. Based on the association between autoimmunity and thyroid dysfunction [49], we also excluded mothers with positive history of autoimmune diseases. The final strictly defined reference population of 403 women was considered adequate for the estimation of reference intervals fulfilling the sample size requirements of Clinical Laboratory Standards (NCCLS) [43]. Additional methodological strengths of our study include examination of distributions and respective application of parametric or nonparametric methods, assessment of outliers, and use of a statistical test to resolve whether separate reference intervals should be calculated for the first and second trimester. Results from this test confirmed the need for trimester-specific reference ranges in agreement to the existing literature and as indicated by normal physiology.

Our study is limited by lack of data concerning the third trimester. Pregnant women were partitioned into trimesters upon entering the study, and thus the resulting sample size ( $n=22$ ) was not adequate for the estimation of reference intervals to a reasonable degree of precision. However, during the second half of gestation TSH levels return to prepregnancy levels and remain stable [50]. In addition, there was only a small number of women $(n=12)$ in less than 8 weeks of gestation, when hCG has a minimal effect on thyroid. Contrary to The National Health and Nutrition Examination Survey in the USA [36], some studies propose that thyroid ultrasound should be used as an additional exclusion criterion to rule out thyroid pathology [51]. In our study, we did not include thyroid ultrasound for the detection of goiter or presence of hypoechogenicity and nodularity of thyroid, since these data were not collected. Finally, an important limitation is the assumption of iodine sufficiency in all women, as we did not evaluate iodine status by urine iodine estimation. However, median urinary iodine excretion (the best parameter to evaluate the adequacy of iodine nutrition in a population) during the last two decades in Greece has been estimated to be over $200 \mu \mathrm{g} / \mathrm{g} \mathrm{Cr}[52,53]$, which is well within normal limits [54]. These findings indicate that, at present, Greece may be considered as an iodine-sufficient country.

\section{Conclusion}

Data from this study establish reference values for Greek Cretan pregnant women and point out the need for laboratoryand geography-specific reference ranges in an effort to detect overt and subclinical thyroid disorders and to evaluate the risk for both obstetric complications and impaired fetal development.

\section{Acknowledgment}

Dr. Leda Chatzi was supported by the EU Integrated Project NewGeneris, 6th Framework Programme, Priority 5: Food Quality and Safety (Contract no. FOOD-CT-2005-016320). NewGeneris is the acronym of the project "Newborns and Genotoxic exposure risks" http://www.newgeneris.org.

\section{References}

[1] D. Glinoer, "The regulation of thyroid function in pregnancy: pathways of endocrine adaptation from physiology to pathology," Endocrine Reviews, vol. 18, no. 3, pp. 404-433, 1997.

[2] C. R. Fantz, S. Dagogo-Jack, J. H. Ladenson, and A. M. Gronowski, "Thyroid function during pregnancy," Clinical Chemistry, vol. 45, no. 12, pp. 2250-2258, 1999.

[3] M. Abalovich, N. Amino, L. A. Barbour et al., "Management of thyroid dysfunction during pregnancy and postpartum: an 
Endocrine Society Clinical Practice Guideline," The Journal of Clinical Endocrinology and Metabolism, vol. 92, supplement 8, pp. S1-S47, 2007.

[4] L. Skjoldebrand, J. Brundin, A. Carlstrom, and T. Pettersson, "Thyroid associated components in serum during normal pregnancy," Acta Endocrinologica, vol. 100, no. 4, pp. 504-511, 1982.

[5] J. Guillaume, G. C. Schussler, and J. Goldman, "Components of the total serum thyroid hormone concentrations during pregnancy: high free thyroxine and blunted thyrotropin (TSH) response to TSH-releasing hormone in the first trimester," Journal of Clinical Endocrinology and Metabolism, vol. 60, no. 4, pp. 678-684, 1985.

[6] R. D. Utiger, "Maternal hypothyroidism and fetal development," New England Journal of Medicine, vol. 341, no. 8, pp. 601-602, 1999.

[7] J. H. Metsman, "Hyperthyroidism in pregnancy," Best Practice and Research, vol. 18, no. 2, pp. 267-288, 2004.

[8] Y. Q. Yan, Z. L. Dong, L. Dong et al., "Trimester-and methodspecific reference intervals for thyroid tests in pregnant Chinese women: methodology, euthyroid definition and iodine status can influence the setting of reference intervals," Clinical Endocrinology, vol. 74, no. 2, pp. 262-269, 2011.

[9] N. S. Panesar, C. Y. Li, and M. S. Rogers, "Reference intervals for thyroid hormones in pregnant Chinese women," Annals of Clinical Biochemistry, vol. 38, no. 4, pp. 329-332, 2001.

[10] J. P. Bocos-Terraz, S. Izquierdo-Álvarez, J. Bancalero-Flores et al., "Thyroid hormones according to gestational age in pregnant Spanish women," BMC Research Notes, vol. 2, article 237, 2009.

[11] R. K. Marwaha, S. Chopra, S. Gopalakrishnan et al., "Establishment of reference range for thyroid hormones in normal pregnant Indian women," An International Journal of Obstetrics and Gynaecology, vol. 115, no. 5, pp. 602-606, 2008.

[12] R. Stricker, M. Echenard, R. Eberhart et al., "Evaluation of maternal thyroid function during pregnancy: the importance of using gestational age-specific reference intervals," European Journal of Endocrinology, vol. 157, no. 4, pp. 509-514, 2007.

[13] J. E. Haddow, G. J. Knight, G. E. Palomaki, M. R. McClain, and A. J. Pulkkinen, "The reference range and within-person variability of thyroid stimulating hormone during the first and second trimesters of pregnancy," Journal of Medical Screening, vol. 11, no. 4, pp. 170-174, 2004.

[14] H. Kurioka, K. Takahashi, and K. Miyazaki, "Maternal thyroid function during pregnancy and puerperal period," Endocrine Journal, vol. 52, no. 5, pp. 587-591, 2005.

[15] C. Cotzias, S. J. Wong, E. Taylor, P. Seed, and J. Girling, "A study to establish gestation-specific reference intervals for thyroid function tests in normal singleton pregnancy," European Journal of Obstetrics Gynecology and Reproductive Biology, vol. 137, no. 1, pp. 61-66, 2008.

[16] G. Lambert-Messerlian, M. McClain, J. E. Haddow et al., "First- and second-trimester thyroid hormone reference data in pregnant women: a FaSTER (First- and Second-Trimester Evaluation of Risk for aneuploidy) Research Consortium study," American Journal of Obstetrics and Gynecology, vol. 199, no. 1, pp. 62.e1-62.e6, 2008.

[17] Y. Gong and B. R. Hoffman, "Free thyroxine reference interval in each trimester of pregnancy determined with the Roche Modular E-170 electrochemiluminescent immunoassay," Clinical Biochemistry, vol. 41, no. 10-11, pp. 902-906, 2008.
[18] D. Springer, T. Zima, and Z. Limanova, "Reference intervals in evaluation of maternal thyroid function during the first trimester of pregnancy," European Journal of Endocrinology, vol. 160, no. 5, pp. 791-797, 2009.

[19] S. L. La'ulu and W. L. Roberts, "Second-trimester reference intervals for thyroid tests: the role of ethnicity," Clinical Chemistry, vol. 53, no. 9, pp. 1658-1664, 2007.

[20] T. Yamamoto, N. Amino, and O. Tanizawa, "Longitudinal study of serum thyroid hormones, chorionic gonadotrophin and thyrotrophin during and after normal pregnancy," Clinical Endocrinology, vol. 10, no. 5, pp. 459-468, 1979.

[21] O. P. Soldin, D. Soldin, and M. Sastoque, "Gestation-specific thyroxine and thyroid stimulating hormone levels in the United States and worldwide," Therapeutic Drug Monitoring, vol. 29, no. 5, pp. 553-559, 2007.

[22] J. S. Dashe, B. M. Casey, C. E. Wells et al., "Thyroid-stimulating hormone in singleton and twin pregnancy: importance of gestational age-specific reference ranges," Obstetrics and Gynecology, vol. 106, no. 4, pp. 753-757, 2005.

[23] A. Price, O. Obel, J. Cresswell et al., "Comparison of thyroid function in pregnant and non-pregnant Asian and western Caucasian women," Clinica Chimica Acta, vol. 308, no. 1-2, pp. 91-98, 2001.

[24] G. S. Dhatt, G. Griffin, and M. M. Agarwal, "Thyroid hormone reference intervals in an ambulatory Arab population on the Abbott Architect i2000 immunoassay analyzer," Clinica Chimica Acta, vol. 364, no. 1-2, pp. 226-229, 2006.

[25] E. N. Pearce, E. Oken, M. W. Gillman et al., "Association of first-trimester thyroid function test values with thyroperoxidase antibody status, smoking, and multivitamin use," Endocrine Practice, vol. 14, no. 1, pp. 33-39, 2008.

[26] R. M. Gilbert, N. C. Hadlow, J. P. Walsh et al., "Assessment of thyroid function during pregnancy: first-trimester (weeks 9-13) reference intervals derived from Western Australian women," Medical Journal of Australia, vol. 189, no. 5, pp. 250253, 2008.

[27] G. Ashoor, N. A. Kametas, R. Akolekar, J. Guisado, and K. H. Nicolaides, "Maternal thyroid function at 11-13 weeks of gestation," Fetal Diagnosis and Therapy, vol. 27, no. 3, pp. 156$163,2010$.

[28] P. Santiago, M. Berrio, P. Olmedo et al., "Reference values for thyroid hormones in the population of pregnant women in jaen (Spain)," Endocrinologia y Nutricion, vol. 58, no. 2, pp. 62-67, 2011.

[29] L. García de Guadiana Romualdo, M. González Morales, M. D. C. Martín-Ondarza González et al., "Evaluation of thyroid function during pregnancy: first-trimester reference intervals for thyroid-stimulating hormone and free thyroxine," Endocrinologia y Nutricion, vol. 57, no. 7, pp. 290-295, 2010.

[30] B. Yu, Q. W. Wang, R. P. Huang et al., "Establishment of self-sequential longitudinal reference intervals of maternal thyroid function during pregnancy," Experimental Biology and Medicine, vol. 235, no. 10, pp. 1212-1215, 2010.

[31] T. Männistö, H. M. Surcel, A. Ruokonen et al., "Early pregnancy reference intervals of thyroid hormone concentrations in a thyroid antibody-negative pregnant population," Thyroid, vol. 21, no. 3, pp. 291-298, 2011.

[32] Z. Baloch, P. Carayon, B. Conte-Devolx et al., "Laboratory medicine practice guidelines. Laboratory support for the diagnosis and monitoring of thyroid disease," Thyroid, vol. 13, no. 1, pp. 3-126, 2003. 
[33] M. Yoshimura and J. M. Hershman, "Thyrotropic action of human chorionic gonadotropin," Thyroid, vol. 5, no. 5, pp. 425-434, 1995.

[34] R. Z. Klein, J. E. Haddow, J. D. Faix et al., "Prevalence of thyroid deficiency in pregnant women," Clinical Endocrinology, vol. 35, no. 1, pp. 41-46, 1991.

[35] L. E. Davis, K. J. Leveno, and F. G. Cunningham, "Hypothyroidism complicating pregnancy," Obstetrics and Gynecology, vol. 72, no. 1, pp. 108-112, 1988.

[36] J. G. Hollowell, N. W. Staehling, W. Dana Flanders et al., "Serum TSH, T4, and thyroid antibodies in the United States population (1988 to 1994): National Health and Nutrition Examination Survey (NHANES III)," Journal of Clinical Endocrinology and Metabolism, vol. 87, no. 2, pp. 489-499, 2002.

[37] D. A. Koutras, M. Alevizaki, A. Tsatsoulis, and A. G. Vagenakis, "Greece is iodine sufficient," The Lancet, vol. 362, no. 9381, pp. 405-406, 2003.

[38] C. A. Spencer, J. S. LoPresti, A. Patel et al., "Applications of a new chemiluminometric thyrotropin assay to subnormal measurement," Journal of Clinical Endocrinology and Metabolism, vol. 70, no. 2, pp. 453-460, 1990.

[39] B. Vaidya, S. Anthony, M. Bilous et al., "Brief report: detection of thyroid dysfunction in early pregnancy: universal screening or targeted high-risk case finding?" Journal of Clinical Endocrinology and Metabolism, vol. 92, no. 1, pp. 203-207, 2007.

[40] D. Glinoer and C. A. Spencer, "Serum TSH determinations in pregnancy: how, when and why?" Nature Reviews Endocrinology, vol. 6, no. 9, pp. 526-529, 2010.

[41] R. Silvio, K. J. Swapp, S. L. La'ulu, K. Hansen-Suchy, and W. L. Roberts, "Method specific second-trimester reference intervals for thyroid-stimulating hormone and free thyroxine," Clinical Biochemistry, vol. 42, no. 7-8, pp. 750-753, 2009.

[42] U. Feldt-Rasmussen, A. S. Bliddal Mortensen, A. K. Rasmussen, M. Boas, L. Hilsted, and K. Main, "Challenges in interpretation of thyroid function tests in pregnant women with autoimmune thyroid disease," Journal of Thyroid Research, vol. 2011, Article ID 598712, 2011.

[43] P. S. Horn and A. J. Pesce, "Reference intervals: an update," Clinica Chimica Acta, vol. 334, no. 1-2, pp. 5-23, 2003.

[44] NCCLS, "How to define and determine reference intervals in the clinical laboratory: approved guideline," NCCLS Document C28-A and C28-A2, Villanova, Pa, USA.

[45] D. Glinoer, M. Riahi, J. P. Grun, and J. Kinthaert, "Risk of subclinical hypothyroidism in pregnant women with asymptomatic autoimmune thyroid disorders," Journal of Clinical Endocrinology and Metabolism, vol. 79, no. 1, pp. 197-204, 1994.

[46] C. A. Spencer, J. G. Hollowell, M. Kazarosyan, and L. E. Braverman, "National Health and Nutrition Examination Survey III Thyroid-Stimulating Hormone (TSH)-thyroperoxidase antibody relationships demonstrate that TSH upper reference limits may be skewed by occult thyroid dysfunction," Journal of Clinical Endocrinology and Metabolism, vol. 92, no. 11, pp. 4236-4240, 2007.

[47] J. P. Grün, S. Meuris, P. De Nayer, and D. Glinoer, "The thyrotrophic role of human chorionic gonadotrophin (hCG) in the early stages of twin (versus single) pregnancies," Clinical Endocrinology, vol. 46, no. 6, pp. 719-725, 1997.

[48] M. R. McClain, G. Lambert-Messerlian, J. E. Haddow et al., "Sequential first- and second-trimester TSH, free thyroxine, and thyroid antibody measurements in women with known hypothyroidism: a FaSTER trial study," American Journal of
Obstetrics and Gynecology, vol. 199, no. 2, pp. 129.e1-129.e6, 2008.

[49] K. Boelaert, P. R. Newby, M. J. Simmonds et al., "Prevalence and relative risk of other autoimmune diseases in subjects with autoimmune thyroid disease," American Journal of Medicine, vol. 123, no. 2, pp. 183.e1-183.e9, 2010.

[50] D. Glinoer and F. Delange, "The potential repercussions of maternal, fetal, and neonatal hypothyroxinemia on the progeny," Thyroid, vol. 10, no. 10, pp. 871-887, 2000.

[51] J. Kratzsch, G. M. Fiedler, A. Leichtle et al., "New reference intervals for thyrotropin and thyroid hormones based on national academy of clinical biochemistry criteria and regular ultrasonography of the thyroid," Clinical Chemistry, vol. 51, no. 8, pp. 1480-1486, 2005.

[52] A. G. Doufas, G. Mastorakos, S. Chatziioannou et al., "The predominant form of non-toxic goiter in Greece is now autoimmune thyroiditis," European Journal of Endocrinology, vol. 140, no. 6, pp. 505-511, 1999.

[53] C. Zois, I. Stavrou, C. Kalogera et al., "High prevalence of autoimmune thyroiditis in schoolchildren after elimination of iodine deficiency in northwestern Greece," Thyroid, vol. 13, no. 5, pp. 485-489, 2003.

[54] F. Delange, "Iodine requirements during pregnancy, lactation and the neonatal period and indicators of optimal iodine nutrition," Public Health Nutrition, vol. 10, no. 12, pp. 15711583, 2007. 


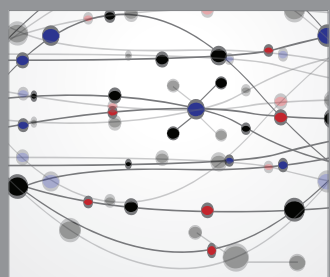

The Scientific World Journal
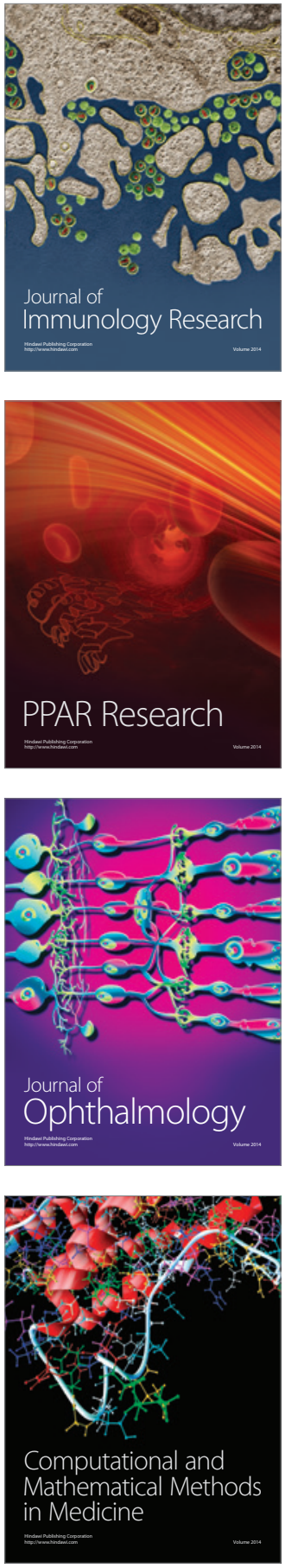

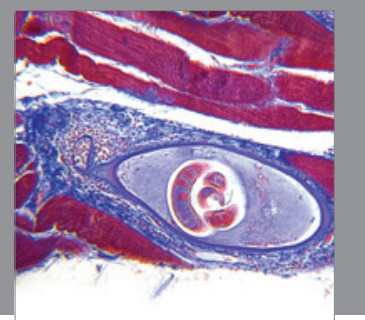

Gastroenterology

Research and Practice
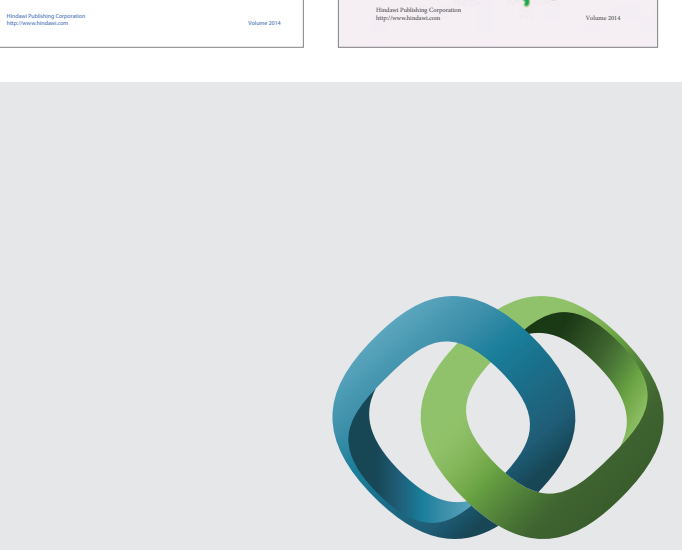

\section{Hindawi}

Submit your manuscripts at

http://www.hindawi.com
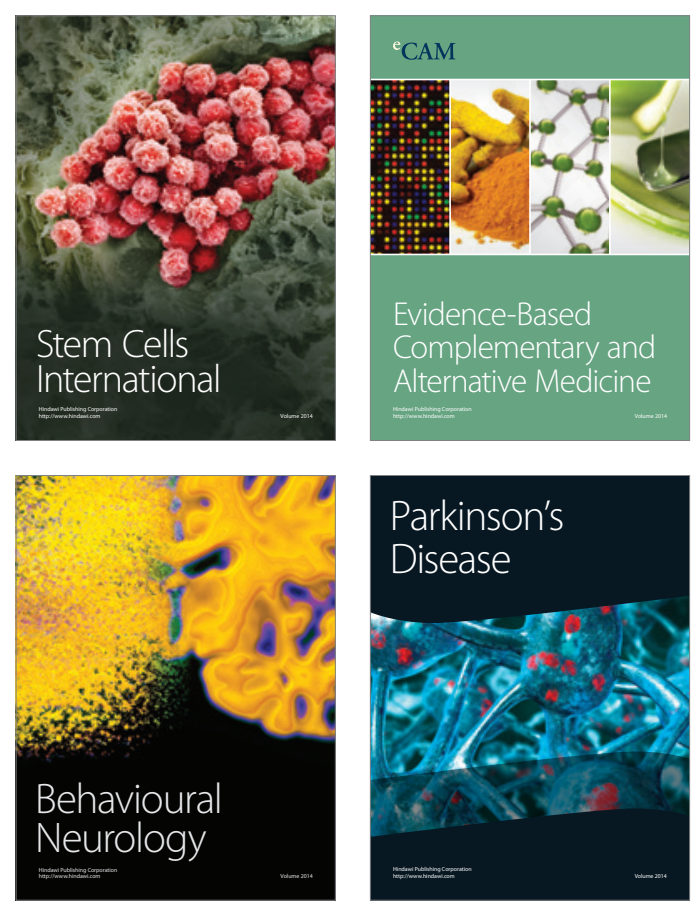

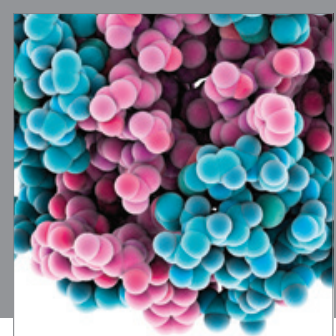

Journal of
Diabetes Research

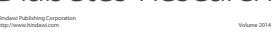

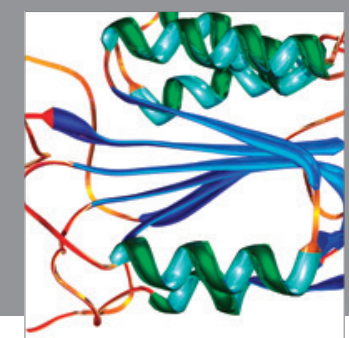

Disease Markers
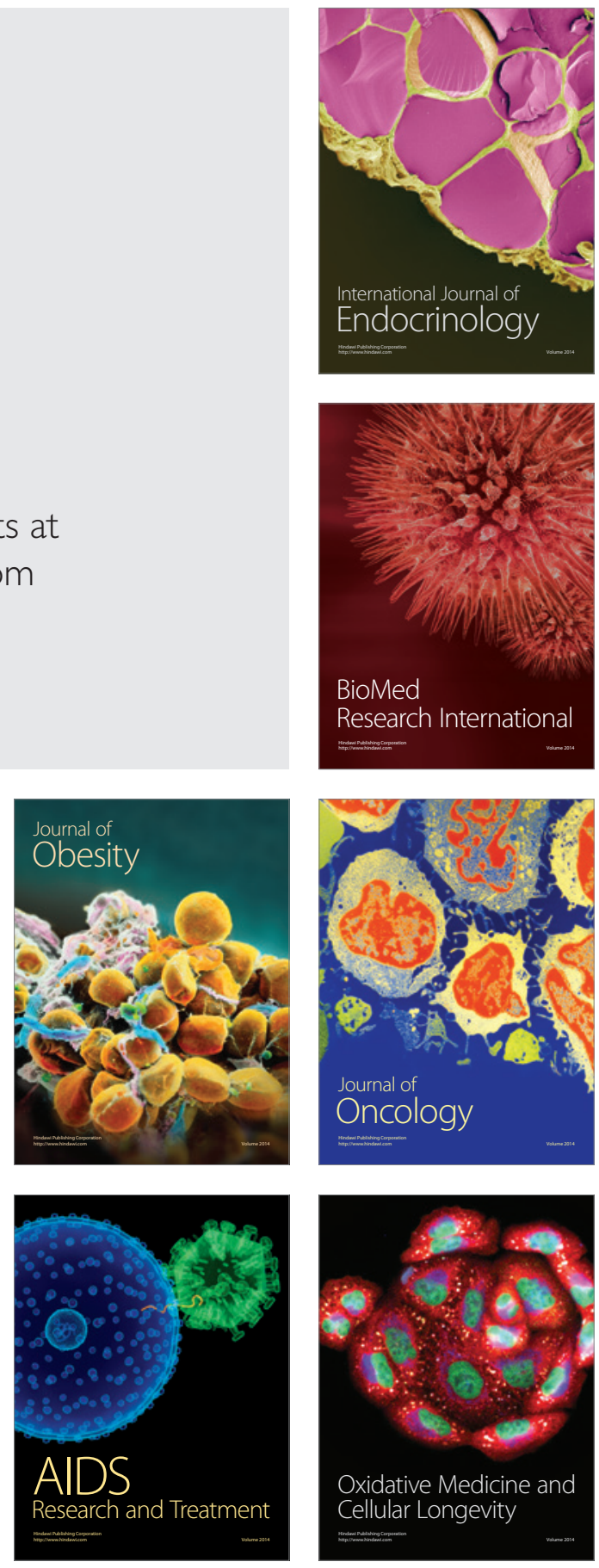